\title{
Management of spontaneous pneumothorax: state of the art
}

\author{
J-M. Tschopp*, R. Rami-Porta\# ${ }^{\#}$, M. Noppen ${ }^{\star}$ and P. Astoul ${ }^{+}$
}

ABSTRACT: Spontaneous pneumothorax remains a significant health problem. However, with time, there have been improvements in pathogenesis, diagnostic procedures and both medical and surgical approaches to treatment.

Owing to better imaging techniques, it is now clear that there is almost no normal visceral pleura in the case of spontaneous pneumothorax, and that blebs and bullae are not always the cause of pneumothorax. In first episodes of primary spontaneous pneumothorax, observation and simple aspiration are established first-line therapies, as proven by randomised controlled trials. Aspiration should be better promoted in daily medical practice. In the case of recurrent or persistent pneumothorax, simple talc poudrage under thoracoscopy has been shown to be safe, cost-effective and no more painful than a conservative treatment using a chest tube. There are also new experimental data showing that talc poudrage, as used in Europe, does not lead to serious side-effects and is currently the best available pleural sclerosing agent.

Alternatively, surgical techniques have considerably improved, and are now less invasive, especially due to the development of video-assisted thoracoscopic surgery. Studies suggest that video-assisted thoracoscopic surgery may be more cost-effective than chest tube drainage in spontaneous pneumothorax requiring chest tube drainage, although it is more expensive than simple thoracoscopy and requires general anaesthesia, double-lumen tube intubation and ventilation.

Recommendations are made regarding the treatment of pneumothorax. In secondary or complicated primary pneumothorax, i.e. recurrent or persistent pneumothorax, some diffuse treatment of the visceral pleura should be offered, either by talc poudrage under thoracoscopy or by video-assisted thoracoscopic surgery. Moreover, all of these new techniques should be better standardised to permit comparison in randomised controlled studies.

KEYWORDS: Spontaneous pneumothorax, state of the art

pontaneous pneumothorax (SP) is defined as the presence of air in the pleural cavity. It is divided into primary SP (PSP) and secondary SP (SSP). SSP is associated with underlying lung diseases such as cystic fibrosis, chronic obstructive pulmonary disease (COPD), AIDS, etc. There are, therefore, two distinct epidemiological forms of SP, PSP, with a peak incidence in young people, and SSP, with a peak incidence in those aged $>55$ yrs [1].
Traumatic pneumothoraces (accidental or iatrogenic) $[2,3]$ are not discussed here.

PSP remains a significant health problem, with an annual incidence of $18-28$ per 100,000 population in males and $1.2-6.0$ per 100,000 population in females [4]. The annual incidence of SSP is 6.3 per 100,000 population in males and 2.0 per 100,000 population in females [5], with incidences varying over time, e.g. during the AIDS-related Pneumocystis carinii pneumonia of the 1980s and

Previous articles in this series: No. 1: Bolliger CT, Sutedja TG, Strausz J and Freitag L. Therapeutic bronchoscopy with immediate effect: laser electrocautery, argon plasma coagulation and stents. Eur Respir J 2006; 27: 1258-1271. No. 2: Vergnon J-M, Huber RM and Moghissi K. Place of cryotherapy, brachytherapy and photodynamic therapy in therapeutic bronchoscopy of lung cancers. Eur Respir J 2006; 28: 200-218. No 3: F. Rodriguez-Panadero, J.P. Janssen and P. Astoul. Thoracoscopy: general overview and place in the diagnosis and management of pleural effusion. Eur Respir J 2006; 28: 409-421.

European Respiratory Journal Print ISSN 0903-1936 Online ISSN 1399-3003
AFFILIATIONS

*Valais Pneumology Centre, CransMontana, Switzerland

\#Thoracic Surgery Service, Mutual Hospital of Terrassa, University of Barcelona, Terrassa, Spain, "Interventional Endoscopy Clinic, Anaesthesiology Dept and Respiratory Division, University Hospital AZ VUB, Brussels, Belgium ${ }^{+}$Dept of Pulmonary Diseases and UPRES 3287, Division of Thoracic Oncology, Saint Marguerite Hospital, Marseille, France.

CORRESPONDENCE J-M. Tschopp Réseau Santé Valais Centre Valaisan de Pneumologie 3963 Crans-Montana Switzerland Fax: 41276038181 E-mail: Jean-marie.tschopp@ admin.vs.ch

Received: January 302006 Accepted: May 032006 
1990s [6, 7]. The mortality of SP can be high, especially in older subjects and those with SSP [6]. The course of SP remains unpredictable, with a recurrence rate ranging $25-54 \%[5,8]$.

This high recurrence rate stimulated the development of many different therapeutic approaches (table 1), including medical thoracoscopy, a simple and minimally invasive technique, and thoracotomy and video-assisted thoracoscopic surgery (VATS), requiring an operating theatre, three or four points of entry and assisted ventilation with double-lumen tube intubation. However, in order to prevent pneumothorax recurrences, all of these techniques usually combine some kind of pleurodesis, either chemical or mechanical, with pleural abrasion or pleurectomy $[9,10]$.

\section{CLINICAL MANIFESTATIONS AND PATHOPHYSIOLOGY}

\section{Primary spontaneous pneumothorax}

Diagnosis of PSP is usually made by chest radiography in the case of sudden chest pain and/or dyspnoea. Contrary to common belief [4], physical activity does not play a role in PSP. Diagnosis is not improved by expiratory chest radiography [11]. Unlike in SSP, dyspnoea is a rare complaint unless there is complete or tension pneumothorax. Smoking is an important risk factor for PSP. The lifetime risk of developing pneumothorax in smoking males is $12 \%$, compared with $0.1 \%$ in nonsmoking males [12, 13]. Recently the British Thoracic Society (BTS) Pleural Disease Group strongly emphasised the relationship between the recurrence of pneumothorax and smoking in order to encourage young patients to stop smoking [4].

The pathophysiology of pneumothorax remains unknown. The general assumption that PSP is the result of rupture of bullae has recently been debated [3]. In 1937, SATTLER [14] identified bullae on the visceral pleura using thoracoscopy, and concluded that air leakage leading to pneumothorax was located in these bullae. Since then, surgical bullectomy has been considered a necessary treatment of pneumothorax, although histopathological analysis of surgically resected subpleural blebs or bullae has not always demonstrated defects responsible for the air leakage in the visceral pleura or resected bullae $[15,16]$. JANSSEN et al. [17] compared video thoracoscopic findings in patients with a first episode with those with recurrent PSP. They found no more blebs or bullae in recurrent PSP, suggesting that blebs and bullae are not a major risk factor for pneumothorax. As to the results of

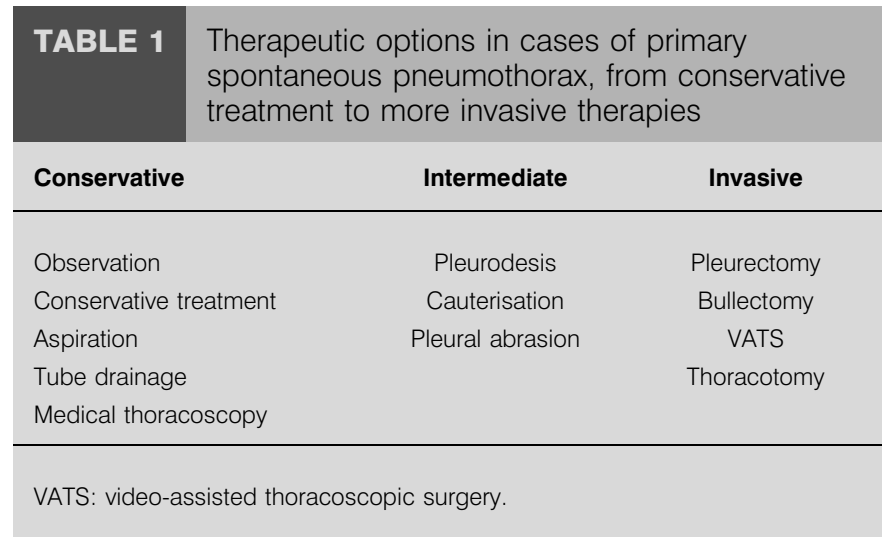

bullectomy alone as a treatment of PSP, three studies, which were not randomised, suggest that bullectomy without additional pleurodesis or pleurectomy does not prevent recurrence as effectively as combining the two techniques [18-20]. The improvement in imaging using computed tomography (CT) has shown diffuse and bilateral blebs in patients cured of unilateral PSP [21, 22]. These changes are generally called emphysema-like changes (ELCs). ELCs were found on CTs in $81 \%$ of nonsmoking non- $\alpha_{1}$-antitrypsindeficient males with previous PSP, and in only $20 \%$ of ageand smoking-matched control subjects without PSP [23]. These smoking-related changes might be the site of lung tissue destruction, and contribute to the occurrence of SP. However, there is no proof that ELCs are the unique cause of pneumothorax. Smoking provokes small airway disease, i.e. bronchiolitis located in small airways. This may lead to a check valve mechanism, with air trapped in small airways because of the narrowed inflamed small airways. In the case of a higher pressure difference, such as atmospheric pressure changes [24], rupture leading to pneumothorax might occur in these peripheral airways. More recently, NopPEN et al. [25] described a case of recurrent PSP in which no air leak or ELCs could be demonstrated on the visceral pleura. Autofluorescence thoracoscopy allowed visualisation of extensive lung areas with subpleural fluoresceine accumulation suggesting the presence of substantial areas of lung parenchymal abnormality.

In summary, the location of the unique or diffuse sites of air leakage leading to PSP is not known. Distal airway inflammation due to cigarette smoking seems to play a key role. ELCs are diffuse, and bilateral subpleural changes are found in PSP. Is the porosity of the visceral pleura increased in patients with PSP compared to normal subjects, as suggested by OHATA and SUZUKI [16]? Thus it is not surprising that the treatment of SP remains the subject of ongoing debate. However, it seems reasonable to assume that bullectomy of unruptured bullae has not been proven to be necessary to prevent recurrence, whereas pleurodesis, which produces a diffuse pleural symphysis, might be effective against any of these potential causes of pneumothorax.

\section{Secondary spontaneous pneumothorax}

Many diseases can provoke SSP (table 2). In COPD patients, its incidence corresponds to the incidence of COPD in the general population. SSP usually occurs with dyspnoea or respiratory insufficiency, and can be life-threatening because of the poor respiratory reserve of these patients $[26,27]$. It often requires immediate treatment. It is accompanied by ipsilateral chest pain, hypoxaemia or hypotension, or even hypercapnia [28]. Pneumothorax should always be excluded in the case of decompensated COPD or cystic fibrosis [29]. Diagnosis is by postero-anterior chest radiography. In the case of doubt, the diagnosis should always be confirmed by a CT scan [30] as it might be harmful to delay treatment of SSP, at least with a chest tube.

As with PSP, the pathophysiology of SSP is multifactorial and remains poorly understood. As recently stated, air enters the pleural space through ruptured alveoli as a result of peripheral lung necrosis, as in P. carinii pneumonia [31]. However, not only $P$. carinii pneumonia but also pulmonary tuberculosis enhance the risk of pneumothorax in AIDS patients [32]. 


\begin{tabular}{l} 
TABLE 2 Aetiology of secondary spontaneous \\
pneumothorax \\
Airway disease \\
Chronic obstructive pulmonary disease \\
Cystic fibrosis \\
Acute severe asthma \\
Infectious lung disease \\
Pneumocystis carinii peumonia \\
Tuberculosis \\
Necrotising pneumonia \\
Interstitial lung disease \\
Sarcoidosis \\
Idiopathic pulmonary fibrosis \\
Histiocytosis $X$ \\
Lymphangioleiomyomatosis \\
Connective-tissue disease \\
Rheumatoid arthritis \\
Ankylosing spondylitis \\
Polymyositis/dermatomyositis \\
Scleroderma \\
Marfan's syndrome \\
Ehlers-Danlos syndrome \\
Cancer \\
Lung cancer \\
Sarcoma \\
\hline
\end{tabular}

Catamenial pneumothorax is a special case of SSP occurring in young females. Interestingly, a prospective study showed that endometriosis could easily be found on the diaphragm but less frequently on the visceral pleura [33].

With incomplete knowledge of the pathophysiolgy of pneumothorax, there is considerable controversy concerning its best treatment. However, all agree that there are two aims when treating pneumothorax: 1) to remove air from the pleural space if necessary (PSP is rarely a medical emergency), and 2) to prevent recurrence of pneumothorax, whatever the method. Not every patient with a first episode of pneumothorax should be treated by air removal unless there is a large pneumothorax with a symptomatic patient. If air removal is justified, three randomised controlled trials have convincingly shown that simple aspiration is equally as effective as traditional chest tube drainage [34-36], with an immediate success rate of $\sim 80 \%$. It should, therefore, be proposed as a first-line therapy in uncomplicated first episodes of pneumothorax (fig. 1). For simple observation, the authors are not aware of any large study that has attempted to measure its success rate.

\section{TREATMENT BY PLEURODESIS WITH OR WITHOUT THORACOSCOPY}

There are broad variations in the management of recurrent SP, depending on the specialty of the responsible physician and the availability of therapeutic options, including VATS [37]. The SP management guidelines of the British Thoracic Society [4, 38] and American College of Chest Physicians (ACCP) [39] are poorly used in clinical practice $[40,41]$.

There is good consensus and clinical evidence that PSP recurrence prevention should be proposed after a first

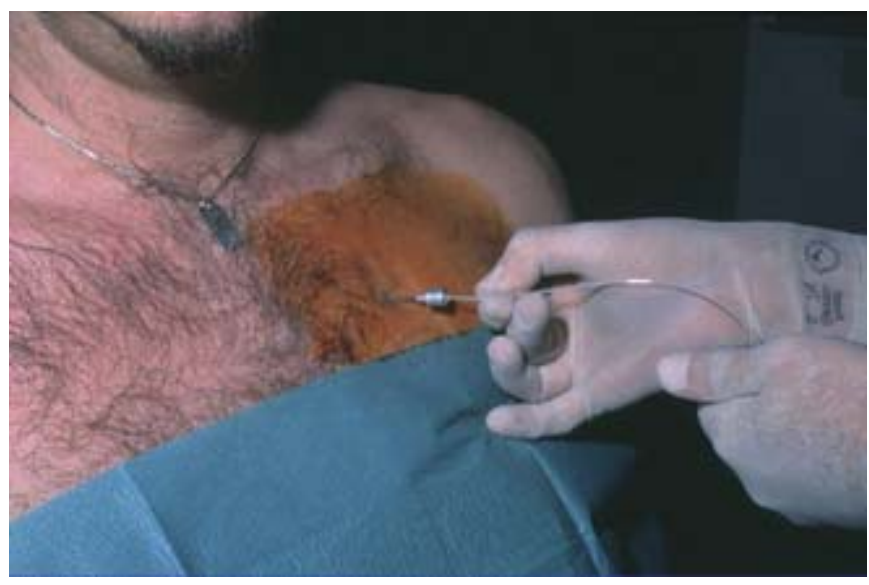

FIGURE 1. Simple aspiration as first-line effective therapy in uncomplicated episodes of primary spontaneous pneumothorax.

recurrence, especially in patients with professional risks [42]. Thus it is recommended by most physicians after the first episode in the case of SSP [4, 39]. However, the optimal procedure for preventing such recurrences remains controversial mainly due to the lack of large randomised prospective controlled studies comparing various recurrence prevention methods, i.e. VATS bullectomy plus pleurodesis versus simple talc poudrage under thoracoscopy. The role of simple thoracoscopy in the treatment of SP is discussed here.

\section{PRIMARY SPONTANEOUS PNEUMOTHORAX}

The therapeutic challenge in the management of PSP is to prevent recurrence, which occurs particularly frequently after a second episode $[3,5,8]$. A randomised study comparing the recurrence of pneumothorax after drainage alone with that after drainage plus tetracycline or talc found recurrence rates of 36,13 and $8 \%$, respectively [43]. More recently, in a multicentric randomised study, the European Study on Medical Video-Assisted Thoracoscopy compared recurrence rates in patients with PSP treated by simple pleural drainage versus thoracoscopic talc poudrage. They found recurrence rates of 34 and $5 \%$, respectively, after a thorough follow-up of 5 yrs in both groups [44]. Moreover, pain during and 1 month after hospitalisation, as well as working incapacity, were not higher in the thoracoscopic talc poudrage group (fig. 2). The same was true for the total costs of this procedure compared to chest tube drainage, even if the authors did not take into account the higher cost of rehospitalisation in those patients only conservatively treated by chest tube.

After a first recurrence, the likelihood of subsequent recurrences increases progressively, up to $62 \%$ for a second recurrence and $83 \%$ for a third [45]. Such high recurrence rates, especially after a second episode, have stimulated the search for better techniques that achieve effective pleural symphysis, taking into account the fact that CT or thoracoscopic evidence of bullae during evaluation of SP is not predictive of recurrence, and do not provide the basis for decisions regarding surgical resection of ELCs [17, 29, 46].

\section{Mechanisms of pleurodesis}

Pleurodesis for the management of SP is intended to achieve symphysis between parietal and visceral pleura and to prevent 


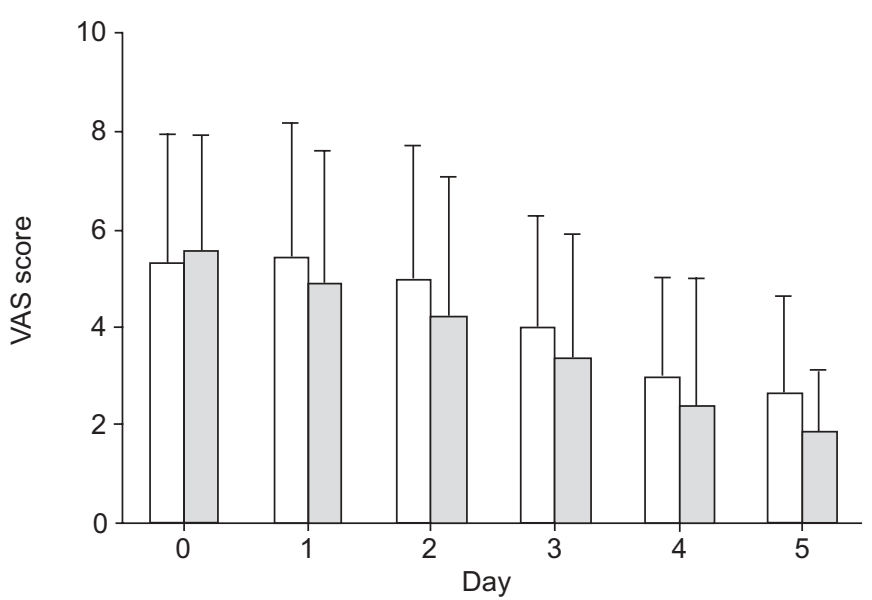

FIGURE 2. Visual analogue scale (VAS) pain score for thoracoscopic talcage $(\square)$ and pleural drainage ( $\square$ ) during and after each procedure. Data are presented as mean $\pm \mathrm{SD}$. Pain was not significantly higher after thoracoscopic talcage than pleural drainage provided use of opioids in both groups. Adapted from [44]

relapse of pneumothorax. Mechanical pleural abrasion or pleurectomy can damage the mesothelial layer and achieve symphysis. However, it is known from more recent studies that the mesothelium itself can act as the initiator of the biological cascade leading to fibrinogenesis [47]. The cellular and molecular mechanisms involved in pleurodesis include: activation of the coagulation cascade of the pleura; fibrin deposition; fibroblast recruitment, activation and proliferation; and collagen deposition [48]. These mechanisms leading to pleurodesis may be specific to the agent used, but there is a common final pathway in the mesothelial cells themselves, activating the pleural coagulation cascade, resulting in fibrin networks and proliferation of fibroblasts. The exact pathogenetic mechanism and factors that influence the outcome of pleurodesis are not well known. However, it is clear that the sclerosing agent must reach the maximum possible surface area of normal mesothelium in order to obtain the best pleural symphysis. This is also the reason why much lower doses of sclerosing agent are required to induce pleurodesis in pneumothorax (in which the mesothelial surface is almost completely preserved) than in malignant pleural mesothelioma [48].

\section{Pleural abrasion}

There are few studies regarding pleurodesis, performed by mechanical gauze abrasion, alone without treatment of ELCs. A study carried out on mongrel dogs compared various methods of pleurodesis, e.g. tetracycline, talc poudrage, mechanical abrasion, neodymium/yttrium-aluminium-garnet laser photocoagulation and argon beam electrocoagulation of the parietal pleura. At the 1-month evaluation, mechanical abrasion was the only method of pleural symphysis comparable with talc poudrage [49]. The anatomical and histopathological results of four different methods of pleurodesis (talc poudrage, talc slurry, focal gauze abrasion by limited thoracotomy and mechanical abrasion by thoracoscopy using a commercially available pleural abrader) were measured in an animal model (dogs). Pleurodesis scores (on a scale of 0-4) were $3.0 \pm 0.7$ for talc poudrage $(\mathrm{p}<0.05$ compared with talc slurry), $2.2 \pm 1.7$ for thoracotomy and $1.6 \pm 1.1$ for talc slurry. Adhesions produced by gauze abrasion during thoracotomy were mostly peri-incisional, and abrasion using the pleural abrader was unsatisfactory [50].

\section{Intrapleural instillation of sclerosing agents}

The ideal pleural sclerosing agent for management of recurrent PSP should be effective, easily administered, safe, inexpensive and widely available. The most commonly used have included antibiotics (tetracyclines), silver nitrate $(\mathrm{SN})$ and talc preparations. However, experimental studies on animals have shown tetracyclines to be less efficient than talc preparations at inducing pleurodesis [49], and are no longer available [51]. Erythromycin could be a potential candidate as a pleural sclerosant but this requires further clinical trials [52].

SN has shown superiority as a sclerosing agent in experimental studies, compared with tetracycline [53] and talc slurry [54, 55]. In a clinical study comparing $\mathrm{SN}$ and tetracycline pleurodesis, there were no differences in recurrence frequency, but the SN group exhibited prolonged hospitalisation and more sideeffects [56], probably due to the systemic inflammatory response involving increased lactate dehydrogenase, interleukin (IL)-8 and vascular endothelial growth factor production [57]. Recently, intrapleural injection of $\mathrm{SN}$ into rabbits produced a more intense acute pleural reaction than intrapleural talc slurry, with higher white blood cell and IL-8 levels in pleural fluid, mainly within the first $6 \mathrm{~h}$. Macroscopic and microscopic pleurodesis scores were significantly greater in rabbits that received SN. However, the distribution of thick and thin collagen fibres did not differ between the two groups [57]. Taking into account the fact that two rabbits developed haemothorax and six developed atelectasis, further experimental studies are required in order to better define the correct SN dosage. Moreover, experimental and clinical studies are required to compare intrapleural $\mathrm{SN}$ injection with talc poudrage in the macroscopically and microscopically obtained symphysis and also the cytokines involved and process of fibrogenesis [58].

\section{Pleurodesis via a chest tube}

Administration of a sclerosing agent via a chest tube is an acceptable approach for pneumothorax prevention in patients wishing to avoid surgery, and for those patients with increased surgical risk (e.g. severe comorbidity or uncontrollable bleeding diathesis) [37, 39]. Success rates using tetracycline, minocycline, doxycycline and talc slurry are intermediate between those obtained with chest tube drainage alone and thoracoscopic treatment $[59,60]$.

After dilution in isotonic saline, talc may be administered into the pleural space via a chest tube (talc slurry) or by talc poudrage via thoracoscopy. Although talc slurry is a commonly employed technique, there are several drawbacks, including prolonged pleural drainage and inhomogeneity of talc deposition in the pleural space following talc slurry instillation [61,62]. The distribution of talc slurry may lead to loculation and incomplete symphysis. Its major advantage is simplicity as it can be performed at the bedside. However, other practical issues should be discussed when considering talc slurry administration. Standardisation of talc administration via chest tube is problematic since physicians use varying 
doses of talc and isotonic solutions, with or without drain clamping, and poor control over the amount of talc left in the chest tube. When considering the distribution of talc, the techniques utilised are also quite variable. Some physicians believe that talc is automatically distributed uniformly within the pleural space, whereas others suggest that patients should be rotated in order to distribute the talc more evenly [63]. All of these questions remain controversial.

\section{Talc pleurodesis via thoracoscopy}

Talc remains the most inexpensive and efficient agent for pleurodesis [44, 49, 50, 61]. Except in the USA, sterile asbestosfree talc is widely used to prevent SP recurrences [44, 64-68]. As with the other agents, chest pain and fever are the most common minor adverse effects. Among acute side-effects, respiratory failure and death have been described following talc poudrage or slurry [69-72].

In a comprehensive review of the literature, SAHN [73] found acute respiratory failure in $0.15 \%$ (one out of 659 ) of patients treated with talc poudrage for pneumothorax [74]. Although there are multiple possible causes, related or unrelated to talc particles, of the development of such respiratory failure following pleurodesis, it has been postulated that intrapleural talc moves into the parietal pleural lymphatics and is transported to the mediastinal lymph nodes and thoracic duct, where it enters the systemic circulation, resulting in a systemic inflammatory process leading to acute respiratory distress syndrome [57].

In an experimental animal study, WEREBE et al. [75] showed that systemic absorption of talc occurs. However, the elementary composition and size distribution of talc particles differs from one mine to another, and this could result in differences in pleural permeability and systemic dispersion of particles after intrapleural injection [76]. More recently, another experimental animal study using calibrated talc for pleurodesis and repeating the same protocol did not show any systemic dissemination of talc particles (fig. 3) [75, 77].

Another explanation for such a systemic inflammatory reaction could be the transpleural transfer of talc inducing lung inflammation, as shown with talc slurry in animal models [78]. However, as these experimental results were obtained in small animals, and may be due to different variations in the visceral pleura, it would be premature to extrapolate them to humans. Moreover, the technique of intrapleural instillation of talc seems to be questionable: talc slurry is a blind method for pleural symphysis, delivering a sclerosing agent under high pressure, which can damage pleura and regional organs (lung, pericardium, diaphragm, mediastinum, etc.) and allows systemic dissemination of talc.

Another possible mechanism could be a systemic inflammatory response induced by intrapleural production of cytokines absorbed by the systemic circulation [57].

However, a recent study in humans compared mixed talc (most particles $<15 \mu \mathrm{m}$, corresponding to the talc commonly used in the USA and UK) first with tetracycline and then with graded talc (most particles $>25 \mu \mathrm{m}$, corresponding to the European standard) and clearly showed that mixed talc produced more systemic inflammation, as measured by hypoxaemia, contralateral lung inflammation and C-reactive protein, than tetracycline. When comparing mixed talc with graded talc, they found the same results, showing that graded talc induces significantly less systemic effects. This strongly suggests that the graded talc currently in use in Europe induces less morbidity, and explains why side-effects have almost never been described by European physicians who have been performing talc poudrage by thoracoscopy for $>70$ yrs [79].

Although talc remains in the pleural space for a long time after administration, there appear to be relatively few long-term effects, in particular impairment of lung function $[65,80]$.

\section{SECONDARY SPONTANEOUS PNEUMOTHORAX}

The occurrence of SSP in patients with underlying disease, such as COPD, may be life-threatening. Hospitalisation is often necessary. Some treatment, such as chest tube insertion and pleurodesis, is mandatory, especially after a first episode [39,
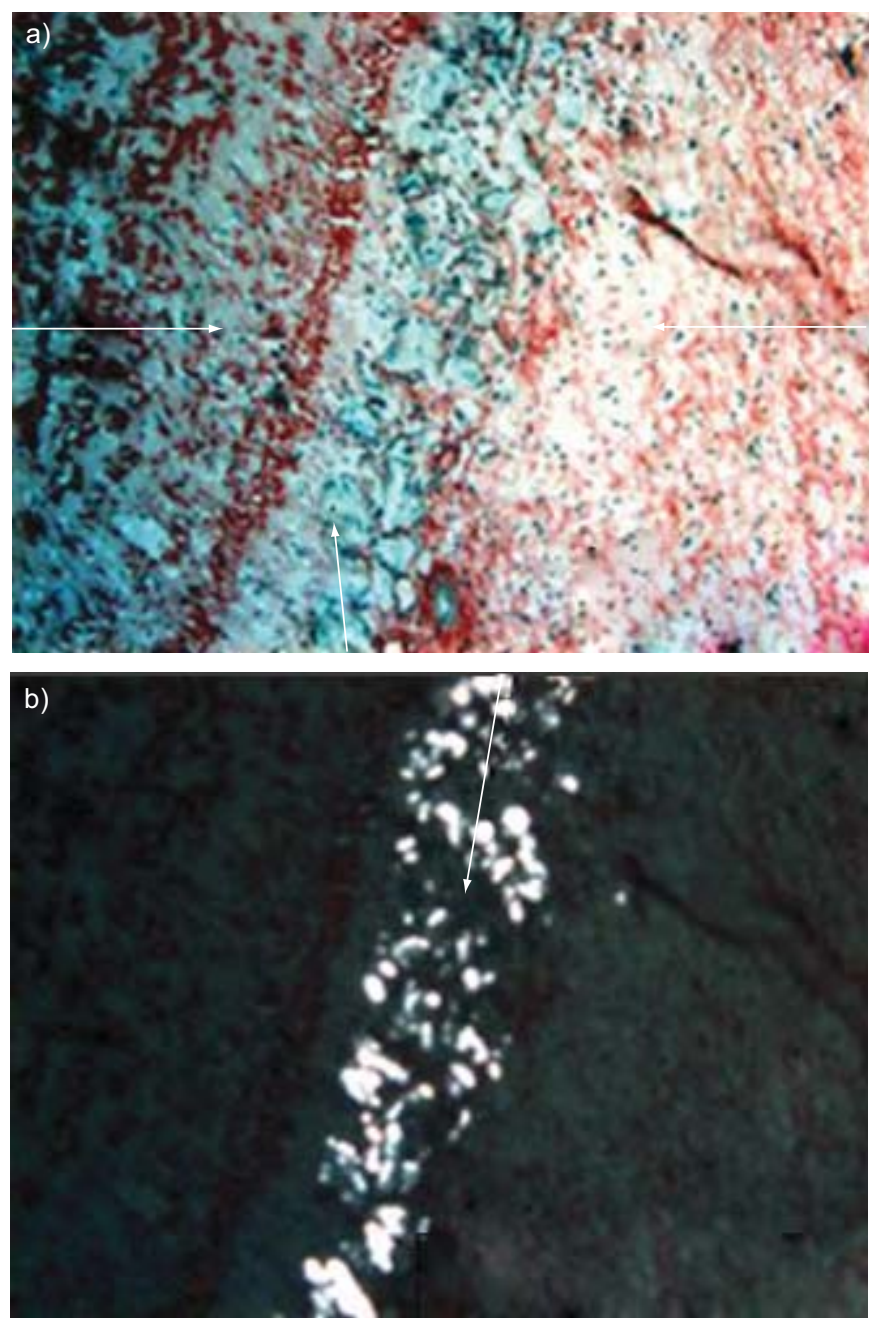

FIGURE 3. Photomicrographs showing talc pleurodesis in goats: a) trichrome staining; and b) polarised light. Calibrated talc, as currently used in Europe produces tight pleurodesis without systemic dissemination of talc (courtesy of $P$ Astoul). The left- and right-hand horizontal arrows indicate the thickness of the parietal and visceral pleura, respectively, and the other arrows talc particles inside the pleural symphysis. 


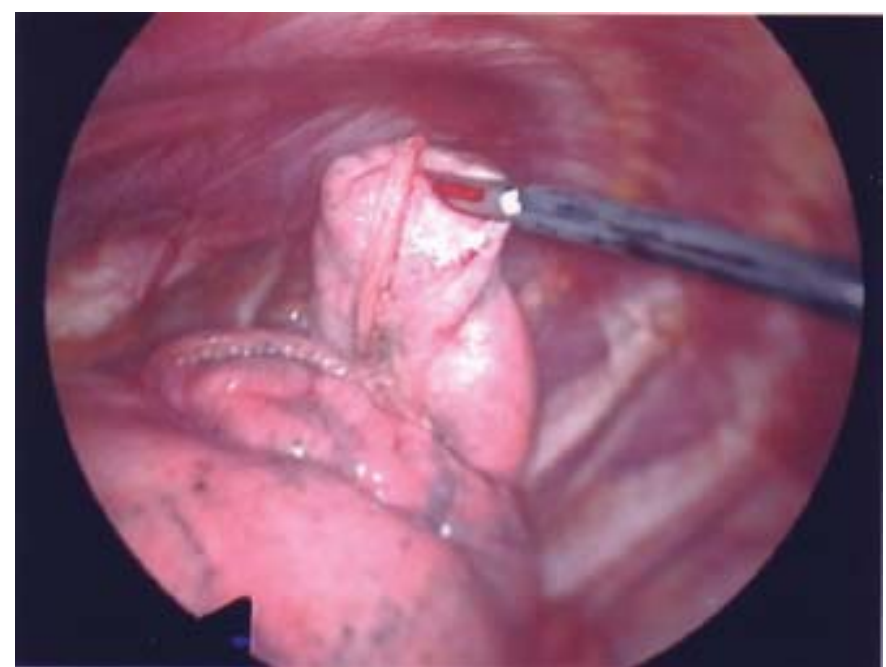

FIGURE 4. Wedge resection of apical bullous lesions of the lung with mechanical stapler, in a case of pneumothorax.

81]. As much as $40-50 \%$ of these patients will undergo a second and dangerous episode of pneumothorax if pleurodesis is not performed [46]. A thoracoscopic approach (medical or surgical) with pleurodesis (pleural abrasion, partial pleurectomy or talc poudrage) is generally preferred over instillation of a sclerosing agent through a chest tube [82]. Recently, LEE et al. [83] showed that talc poudrage under thoracoscopy is safe, even in patients with advanced COPD, confirming previous studies $[84,85]$.

However, there are no randomised controlled trials addressing management of SSP. Considering the importance of SP in patients with underlying diseases, in particular COPD, multicentric trials are needed to perform formal decision analyses, and assess the value of different management approaches [86].

\section{SURGICAL TREATMENT OF SPONTANEOUS PNEUMOTHORAX}

Surgical treatment by thoracotomy used to be the last therapeutic resort for SP that could not be treated by lesser procedures, such as observation, manual aspiration, drainage or thoracoscopy. It was the treatment of choice for recurrent ipsilateral or contralateral pneumothorax, or pneumothorax with persistent air leak, bilateral synchronous pneumothorax or pneumothorax occurring in persons whose professions resulted in exposure to atmospheric pressure changes, pilots and scuba-divers, for example. The surgical approach was through either standard posterolateral thoracotomy, or, more frequently, smaller incisions. The therapeutic procedure consisted of resection of lung lesions, blebs and bullae, and some sort of pleural procedure: partial or complete pleurectomy, pleural abrasion, or chemical pleurodesis. Recurrence rates with these procedures in large series of patients after a followup of $\leqslant 20$ yrs used to be $3-4 \%[87,88]$.

In the early 1990s, the adaptation of most surgical instruments for endoscopic use, and the improvement and miniaturisation of video cameras, introduced radical changes in surgical practice. A new technique, called VATS, retained all the diagnostic and therapeutic potential of traditional thoracoscopy, but allowed the surgeon to perform the same intrathoracic procedures that would be performed through thoracotomy, thus widening enormously the range of therapeutic indications for the endoscopic approach. The endoscopic staplers proved very useful in the treatment of $\mathrm{SP}$, as resection of apical lesions could be carried out easily (fig. 4). This led to a shift towards VATS treatment of SP. Open procedures have been progressively abandoned and reserved for exceptional cases. This is evident when searching for indexed references; most reports on surgical treatment of SP since the mid-1990s deal with VATS. Thoracotomy is seldom reported. A survey among members of the ACCP showed that, in all situations that required surgical treatment for both PSP and SSP, practicing American pulmonologists and thoracic surgeons preferred the video thoracoscopic approach [89]. In 2001, a Delphi study among members of the ACCP again showed a preference for VATS procedures over thoracotomy with very good consensus [39]. However, the latest BTS guidelines consider thoracotomy and pleurectomy the procedures of choice, as they show the lowest recurrence rate, and consider VATS procedures an alternative strategy due to the lack of large controlled clinical trials [4].

\section{Surgical management by thoracotomy}

Although standard posterolateral thoracotomy is still used to treat SP [90], recent reports show that there is a preference for smaller incisions: axillary thoracotomy [91, 92], anterior thoracotomy [93], muscle-sparing lateral thoracotomy [94], and a variety of posterior, lateral and axillary mini-thoracotomy procedures [95]. Midsternotomy for simultaneous treatment of both lungs is performed in $<1 \%$ of cases [95].

The operation is performed under general anaesthesia. The intrathoracic procedure consists of excision of blebs and bullae, usually by stapling, and the treatment of smaller bullous lesions with electrocoagulation or a laser. Treatment of lung lesions is almost invariably associated with some pleural procedure, thought to be important in avoiding recurrences should new parenchymal lesions arise. Mechanical abrasion of the parietal pleura with dry gauze or electrosurgical tip cleaner is the most common procedure. Sometimes, the visceral pleura is also gently rubbed [92,94]. Less common is the addition of chemical pleurodesis with tetracycline, which is applied to the surface of the visceral pleura [94]. Alternatively, some surgeons prefer parietal pleurectomy, usually limited to the upper third or half of the pleural cavity [90]. Finally, some prefer to avoid any type of pleurodesis or pleurectomy and rely exclusively on the treatment of parenchymal lesions [93].

Complication rates range from $0 \%$ in short series of patients [91] to $16 \%$ in larger series [93]. Common complications include persistent air leaks, usually defined as leaks persisting for $>5$ days, and occur in $5-7 \%$ of patients [94, 95], wound infection (1.4-6.7\%) [94], pneumonia $(2.4-8 \%$ ) [93, 94], fever $(1.9-10 \%)[94,95]$, re-operation due to bleeding $(1-2 \%)[90,93]$ and shoulder arthritis (1.9\%) [95]. Other complications, such as residual pneumothorax, urinary tract infection, acute urinary retention, haematoma or neurological deficit, are rare [90]. Mortality occurs in $\sim 1 \%$ of patients with chronic obstructive lung disease and SSP, and is related to medical complications or worsening of their underlying lung disease [93]. 

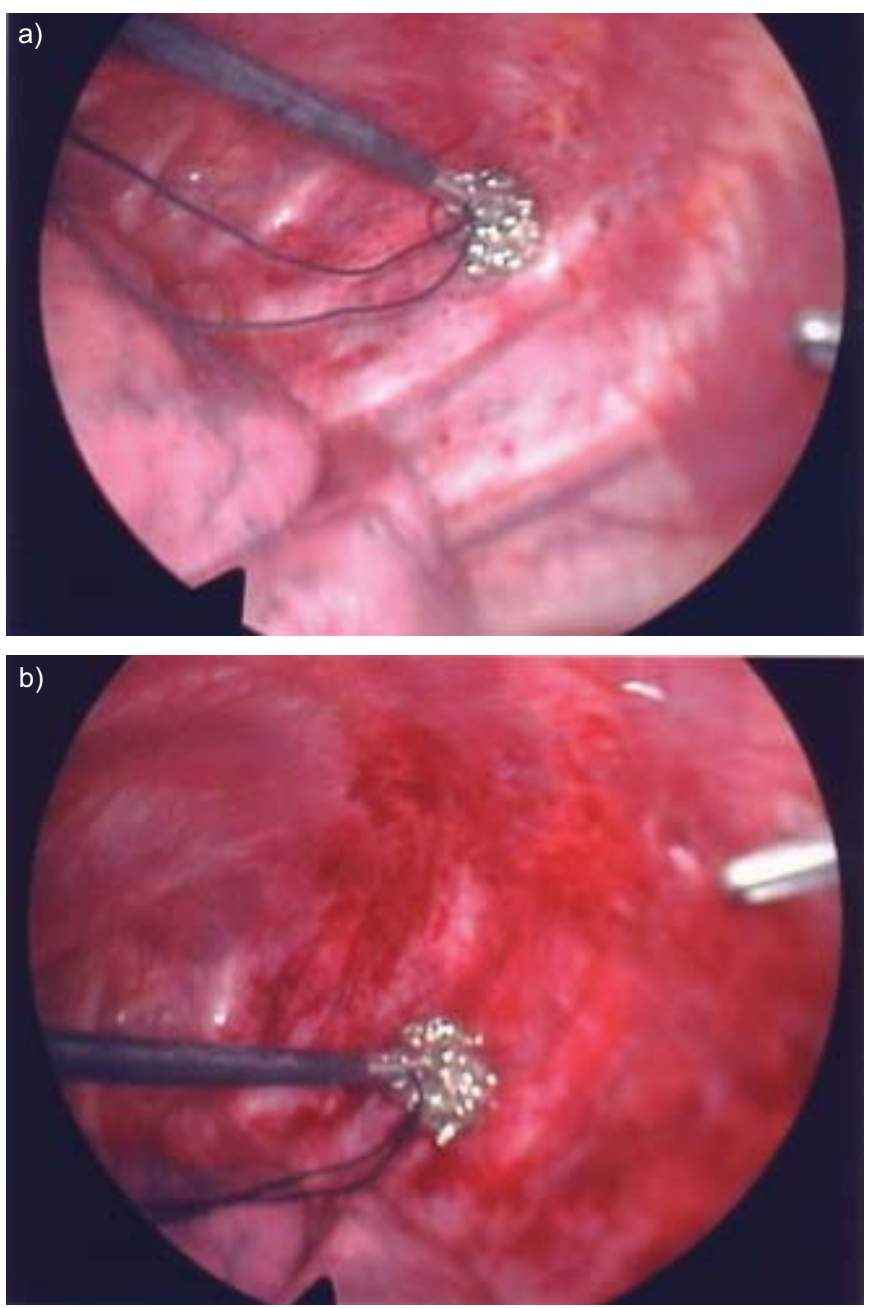

FIGURE 5. Metallic scrubber before mechanical pleural abrasion. Before abrasion, the parietal pleura looks normal (a); as abrasion is in progress, the parietal pleura is reddened and bleeds slightly (b).

Recurrence rates can be as low as 0 [91] or 1\% [95] or rise to $5.3 \%$ [93]. Some authors [94] differentiate between early recurrences (pneumothorax occurring immediately after removal of chest tubes) and late recurrences. In 250 patients treated with ligation or stapling of bullae and different types of abrasion and pleurectomy [90], there were three (1.2\%) recurrences, two $(3.3 \%)$ in 60 patients in whom apical parietal pleurectomy had been performed via a transaxillary approach, and one $(1 \%)$ in 93 patients in whom mechanical abrasion had been carried out. There were no recurrences in the group of 74 patients who had undergone parietal pleurectomy from the hilum to the apex, or among the 23 patients on whom apical pleurectomy had been performed through posterolateral or submammary thoracotomy procedures. In the series of 120 patients who underwent 132 thoracotomy procedures for wedge resection of the parenchymal lesions without pleurodesis or pleurectomy, recurrence occurred in seven $(5.3 \%)$ cases [93], which compares unfavourably with the series of 95 patients treated with stapling resection of blebs and pleural abrasion, in whom recurrence occurred in only one $(1 \%)$ patient [95], and with the larger series of 250 patients, in whom some sort of pleural treatment was added to the excision of lung lesions, in whom recurrence occurred in one patient [90].

\section{Surgical management by VATS}

VATS is usually performed under general anaesthesia and single-lung ventilation. The patient is in the lateral decubitus position and prepared as for standard posterolateral thoracotomy. Three ports are generally necessary, one for the thoracoscope and two for the lung graspers and stapling devices [96]. High-risk patients, usually elderly patients with severe underlying lung disease, can undergo VATS under local and epidural anaesthesia [97] or even under local anaesthesia and sedation [98]. Application of sealants over air leaks and stapled resection of bullae and talc poudrage can be performed safely.

VATS allows performance of the same intrathoracic procedures as performed through thoracotomy [99]. It has the advantage that pleural and lung inspection is more complete than when carried out through limited thoracotomy. A survey among thoracic surgeons of the General Thoracic Surgical Club revealed that VATS was the preferred approach for treatment of recurrent pneumothorax [100].

For the management of blebs and bullae, stapled resection is the most common procedure [18, 19, 101-116]. Other procedures include clipping of pedicled bullae [117, 118], ligation or looping of bullous lesions [101, 103, 104, 118], and electrocautery or laser ablation of blebs and small bullae [104, 112, 118]. These procedures on the lung parenchyma are usually associated with a variety of manoeuvres to create pleurodesis and prevent recurrences. These include parietal pleural abrasion with dry gauze or any other rubbing material (fig. 5) [102-105, 107, 109-111, 113, 114, 116], apical pleurectomy [67, 101-111, 113-116], and chemical, laser or electrocautery pleurodesis $[18,19,67,104,106,114,116]$.

Post-operative complications are similar to those found after thoracotomy and occur in 1 [106] to $27.4 \%$ [113] of patients. The latter represents a meticulous collection of post-operative events, some of which regressed spontaneously, such as pleural effusion or brachial cutaneous nerve palsy, which may be unreported by other groups. In general, the complication rate is $<10 \%[18,101,102,104,105,107,108,110,115]$, and, in some series, there is no morbidity at all [112, 114, 119]. Most series consist of a mixture of patients with PSP and SSP. Those reporting separate complication rates for each group of patients have found higher complication rates for patients with SSP than with PSP: 27.7 versus 6.6\% [106], 25 versus 1.7\% [107], 16 versus $0 \%$ [108], and 33 versus $12 \%$ [109], respectively. Air leak is a frequent complication, especially in SSP, that may require reintervention, either thoracotomy or a second VATS procedure [102, 120]. As with open procedures, mortality is rare and limited to patients with SSP. Although most of them can be extubated at the end of the operation, some require mechanical ventilation, with possible death due to myocardial infarction, heart failure or respiratory failure [108, 120].

Global recurrence rates range from 0 [103, 114] to $10 \%$ [112]. Many of these recurrences are due to failures of the method of treatment. Clipping, ligation and looping of blebs were used early in the experience of different groups and were associated with recurrence rates as high as 11.5 [101] and 22.2\% [118]. 
These methods have not been used in the most recent series. Recurrence rates also seem to be inversely related to the intensity of the treatment; the more procedures performed, especially when lung and pleural procedures are combined, the fewer the recurrences. In an uncontrolled series of 74 patients treated with four different methods, the recurrence rates for each procedure were: ligation of air leak, $11.5 \%$; wedge resection of blebs or bullae, $7.1 \%$; pleurectomy, $6.35 \%$; and pleurectomy plus ligation of air leaks or wedge resection of lesions, $5.6 \%$ [101]. In 113 patients, the only independent predictive factor of recurrence of SP was the failure to identify and resect a bleb at operation [104]. In recent series, the procedure of choice is stapled resection of blebs and bullae, or wedge resection of the tip of the lung when lesions are not identified, and some sort of pleurodesis: mechanical abrasion, apical pleurectomy or patchy electrocoagulation of the parietal pleura. These procedures result in a recurrence rate of $0-5 \%$ [18, 102, 105-108, 110, 113-115, 121]. Pleural procedures alone are associated with higher recurrence rates, $6.3 \%$ for apical pleurectomy [101] and 9.9\% for mechanical pleurodesis [102]. Complete pleurodesis prevents recurrences better than partial pleurodesis. In 339 Vanderschueren stage III and IV patients, PSP was treated with either ligation or stapling of lesions and subtotal pleurectomy or talc poudrage; those treated with talc poudrage showed the lowest recurrence rates: 0 versus $4.5 \%$ for stapling and poudrage, and ligation and poudrage in stage III pneumothorax; and $0.84 \%$ for stapling and poudrage for stage IV pneumothorax. However, the recurrence rates for the same pneumothorax stages when subtotal pleurectomy was performed instead of poudrage were 4.70, 12.19 and 5.26\%, respectively. The same was observed in 93 patients with stage I and II PSP treated with either subtotal pleurectomy or talc poudrage alone, in whom recurrence rates were 6.45 and $4.8 \%$, respectively [67].

Long-term complications include moderate chronic pain, usually located in the area of the trocar incisions, in about a third of patients, especially in those who have undergone pleurectomy as compared with mechanical pleurodesis. However, $<4 \%$ require daily medication [107]. Additionally, $\sim 50 \%$ of patients may experience chest wall paraesthesiae, distinct from wound pain [122]. These chronic complications seem to be due to compression of intercostal nerves during operation. Some authors use trocars for the thoracoscope only, and insert the other instruments through the intercostal incisions in the other ports in order to minimise nerve compression. The use of needlescopic instruments $(2 \mathrm{~mm}$ in diameter) has been found to reduce post-operative wound pain [123] and residual neuralgia [124]. The presence of dense pleural adhesions is an indication for conversion to standard VATS [125]. Although published experience is scarce, needle thoracoscopy seems to be as effective as conventional VATS when there are bullae of $<2 \mathrm{~cm}$ and few pleural adhesions.

Treatment of recurrences varies according to the size of pneumothorax and the presence of air leaks after insertion of chest tubes. For limited pneumothorax in stable patients, rest and observation are recommended. When reoperation is necessary, both repeat VATS and thoracotomy have been performed. In $\sim 50 \%$ of cases, residual bullae or air leaks are found; these are usually stapled or ligated, and pleurodesis by pleurectomy, abrasion or talc poudrage is added. When no lesions are identified, some sort of pleurodesis is performed $[102,104,105,108-110,126,127]$.

\section{Surgical approaches to both lungs}

Simultaneous bilateral pneumothorax and contralateral recurrence are quite often indications for surgical treatment of both sides. This has been carried out using bilateral thoracotomy procedures or VATS, and midsternotomy. A recent report describes the bilateral apical stapling of bullae and apical pleurectomy through an axillary mini-thoracotomy. Once the ipsilateral side is completed, access to the contralateral side is gained across the mediastinum between the first thoracic vertebral bodies and the oesophagus. The contralateral lung apex is grasped and pulled into the opened pleural cavity and apical lesions are resected. The contralateral chest cavity is drained from the opened chest with a tube passing across the mediastinal opening. There were no complications in a series of 13 patients. This procedure would be indicated in patients with lesions limited to the apex of both lungs as a treatment alternative for recurrences after VATS, and when there are known lesions in the contralateral lung, in order to reduce further relapses [128]. A similar approach has been described via VATS. In this case, the passage to the contralateral pleural space is created between the sternum and the pericardium. The procedure was attempted in six patients and was successful and uneventful in four. The other two underwent bilateral VATS due to pleural adhesions [129]. However, a study of six patients represents too small a sample to draw any conclusions. The most common practice is to perform two VATS procedures, in either the lateral decubitus position, with sidechanging after completing one side [130], or the supine position, modifying the sites of the trocars, two on the anterior axillary line and one in the midclavicular line through the second intercostal space [96]. This simultaneous approach is not associated with increased morbidity or prolonged hospital stay compared to staged bilateral VATS [131].

\section{Comparison between thoracotomy and VATS}

There have been two prospective clinical trials comparing thoracotomy and VATS. The first properly randomised trial compared VATS for PSP and SSP with limited partial musclesparing lateral thoracotomy [132]. In the VATS group for PSP, the 72-h decreases in forced expiratory volume in one second and forced vital capacity were significantly lower. This group of patients had a longer operating time, required less analgesics in the first $12 \mathrm{~h}$ post-operatively and had a shorter post-operative hospital stay, but none of these differences were significant. In the group of patients with SSP, none of the differences were significant, except for operating time, which was longer for the VATS group. The authors concluded that VATS was superior to thoracotomy for PSP, but cast doubts on its use in SSP. The second trial was not properly randomised since the patients chose the procedure after the doctor had explained their details [133]. The cost of VATS was higher than the cost of transaxillary mini-thoracotomy, and only partially covered by medical insurance; this may have introduced bias into the selection of the procedure. In this trial, the differences in operating time, amount of analgesia on the first postoperative day, and duration of chest tube placement were not significant, although the operating time and the duration of chest tube placement were shorter for the transaxillary 
mini-thoracotomy group. It was concluded that VATS showed no advantage over mini-thoracotomy.

In uncontrolled trials, some authors have compared their initial experience with VATS treatment of SP with historical series of patients who had undergone thoracotomy, either axillary, limited lateral or posterolateral. In these comparisons, the duration of drainage was generally shorter in the VATS group [107, 121, 134, 135] or the same [136]; the length of hospital or post-operative stay was also shorter [107, 121, 134, $135,137,138]$ or the same $[136,139]$; the operating time was shorter for VATS [121, 135], the same for both procedures [136, 137], or longer for VATS than for thoracotomy [138]; patients who underwent VATS required less narcotic analgesics than those who underwent thoracotomy [107, 134, 137]; postoperative complication rates were lower [134] or higher [137] in the VATS group, or the same in both groups [121]; the recurrence rate was about the same, but there seemed to be more patients with recurrences among those who underwent VATS [121, 134, 135, 138]; the amount of operative bleeding was smaller in the VATS group [121]; patients in the VATS group returned to work earlier [107, 137]; and, finally, VATS was cheaper than thoracotomy [135]. It has been reported that some of these advantages of VATS, such as the shorter duration of drainage and hospitalisation, and earlier return to work, are only valid for patients with PSP [107].

\section{COST-EFFECTIVENESS}

The cost-effectiveness of VATS procedures has mainly been analysed in retrospective studies [140]. In general, VATS is initially more expensive, but a shorter hospital stay may compensate for this. The few cost analyses regarding SP show that VATS seems to be economically justified as an initial procedure instead of insertion of a chest tube, although its initial cost is higher [141, 142]. This also seems to be true for VATS treatment of second episodes of SP [42]. These conclusions are not based on randomised studies and, therefore, need to be confirmed in properly conducted clinical trials. Furthermore, SCHRAMEL et al. [143] undertook a cost-benefit analysis in patients with SP requiring chest tube drainage, comparing such a conservative approach to VATS in two historical series, and found less complications and a cost $42 \%$ lower in the VATS group, casting doubts on the efficacy of a conservative strategy. They also concluded that, if patients with SP had been treated with simple talc poudrage under thoracoscopy, this would have resulted in an additional $62 \%$ reduction in the costs calculated for patients with VATS.

\section{CONCLUSION}

There are many options in the management of SP. Its pathophysiology remains poorly understood. However, it is very well known that PSP is strongly related to smoking in both sexes. No clinician should miss the opportunity of pneumothorax, especially in young people, to encourage smoking cessation. Most young patients continue to smoke after their first episode of PSP, showing that clinical strategies need to be improved in order to better address the needs of this particular age group [144].

There are two aims when treating pneumothorax: 1) to evacuate air, and 2) to prevent recurrence. In first episodes of PSP, there is no doubt that observation and simple aspiration are established first-line therapies, as proven by randomised controlled trials [34, 36]. However, although aspiration has been recommended since the mid-1980s [145, 146], it remains poorly applied and ought to be better promoted in daily medical practice. In the case of failure of aspiration, a chest tube should be inserted and patients referred to special lung units with specialist medical and nursing experience, since intercostal tube placement can lead to serious complications, even death [147-150]. Patients requiring insertion of a chest tube should be informed that simple talc poudrage under thoracoscopy prevents recurrences of pneumothorax without prolongation of hospitalisation or complications, and is more cost-effective than conservative treatment with an intercostal tube, as shown in a randomised controlled trial [44].

In clinical situations such as SSP with potential respiratory insufficiency, recurrent PSP or persistent pneumothorax, treatment to prevent recurrence of pneumothorax is mandatory. There are two main choices, either medical talc pleurodesis by simple thoracoscopy or a surgical approach. Thoracoscopic talc poudrage is a safe procedure, even in complicated SSP [83-85], and would be no more painful than chest tube drainage if thoracoscopists were to improve their skill in treating pain [151]. Recently, a surgical team [64] published the most extensive study on pneumothorax management to date, with $>1,000$ cases, and showed that thoracoscopy under talc poudrage was very successful, with a relapse rate of $5 \%$.

Conversely, it is also true that VATS has been shown to be more cost-effective than chest tube drainage for a similar indication [143], although it is a more expensive procedure than thoracoscopy, requiring general anaesthesia, double lumen tube intubation and ventilation. There is no evidence for routine resection of blebs and bullae, making this procedure very controversial except for very large bullae [3] or when there is some evidence of bullae leakage, such as in persistent pneumothorax. Surgical techniques have improved considerably and are now less invasive. Since the early 1990s, there has been a preference for VATS over thoracotomy, although the number of recurrences after VATS is generally a little higher than after thoracotomy. VATS allows the performance of a wide variety of procedures on lung parenchyma and pleural surfaces. The combination of stapled resection of blebs or bullae and some sort of pleurodesis, especially abrasion or pleurectomy, seems to yield the lowest recurrence rates. VATS for SP has not been adequately compared with thoracotomy in large randomised clinical trials, for either clinical effectiveness or cost. After many years, during which it has proved to be technically feasible to treat SP with reasonable morbidity, the time has come to standardise the surgical technique used and begin large randomised clinical trials to answer three basic questions: 1) whether VATS is definitively superior to thoracotomy; 2) whether it is cost-effective; and 3) the correct time to initiate it. There are also many other potential areas of further research in randomised controlled trials, such as comparing any surgical technique like VATS to thoracoscopy with simple talc poudrage, comparing clamping and nonclamping strategies after air leak cessation, and outpatient use of small catheters connected to Heimlich valves compared with intercostal chest tube drainage following failed aspiration, etc. 
As shown in the present article, thoracic surgeons and pulmonologists must develop more synergies and use randomised controlled trials in order to improve on the knowledge accumulated by both disciplines for the management of pneumothorax, since most studies to date have been nonrandomised controlled studies. This is the only way to answer the rather provocative question asked by surgeons as to whether the tendency to replace simple thoracocoscopy with video-assisted thoracoscopic surgery might not be due to the glory of newer and expensive techniques [64]. In 1997 [152], an editorial welcoming the fifth anniversary of video-assisted thoracoscopic surgery reported, at that time, $>500$ publications on video-assisted thoracoscopic surgery and concluded that most of theses publications represented very little careful scientific evaluation of this new technology. It is now time to evaluate more scientifically an old technique, thoracoscopy, discovered by Jacobeus in 1910 [10], and also video-assisted thoracoscopic surgery, which has been available since 1992. This is the only way to diminish the present confusion regarding the best treatment for pneumothorax [153].

\section{ACKNOWLEDGEMENTS}

The authors would like to thank J. Brunton for comments and suggestions.

\section{REFERENCES}

1 Gupta D, Hansell A, Nichols T, Duong T, Ayres JG, Strachan D. Epidemiology of pneumothorax in England. Thorax 2000; 55: 666-671.

2 Light RW. Management of spontaneous pneumothorax. Am Rev Respir Dis 1992; 148: 245-248.

3 Schramel FMNH, Postmus PE, Vanderschueren RGJRA. Current aspects of spontaneous pneumothorax. Eur Respir J 1997; 10: 1372-1379.

4 Henry M, Arnold T, Harvey J. BTS guidelines for the management of spontaneous pneumothorax. Thorax 2003; 58: Suppl. 2, 39-52.

5 Melton LJ, Hepper NCG, Offord KP. Incidence of spontaneous pneumothorax in Olmsted County, Minnesota: 1950-1974. Am Rev Respir Dis 1979; 29: 1379-1382.

6 Wait MA, Estrera A. Changing clinical spectrum of spontaneous pneumothorax. Am J Surg 1992; 164: 528-531.

7 Byrnes TA, Brevig JK, Yeoh CB. Pneumothorax in patients with acquired immunodeficency syndrome. J Thorac Cardiovasc Surg 1989; 98: 546-550.

8 Sadikot RT, Greene T, Meadows K, Arnold AG. Recurrence of primary spontaneous pneumothorax. Thorax 1997; 52: 805-809.

9 Inderbitzi R. Chirurgische Thorakoskopie. [Surgical Thoracoscopy.] Berlin, Springer-Verlag, 1993.

10 Boutin C, Viallat JR, Aelony Y. Practical Thoracoscopy. Berlin, Springer-Verlag, 1991.

11 Schramel FM, Golding RP, Haakman CD, Sutedja TG, de Jong KA, Postmus PE. Expiratory chest radiographs do not improve visibility of small apical pneumothoraces by enhanced contrast. Eur J Respir Dis 1996; 9: 406-409.

12 Bense L, Eklund G, Wiman LG. Smoking and the increased risk of contracting spontaneous pneumothorax. Chest 1987; 92: 1009-1112.
13 Jansveld CA, Dijkman JH. Primary spontaneous pneumothorax and smoking. BMJ 1975; 4: 559-560.

14 Sattler A. Zur Behandlung der Spontanpneumothorax mit besonderer Berücksichtigung der Thorakoskopie. [Treatment of Spontaneous Pneumothorax from the Point of View of Thoracoscopy]. Beitr Klin Tuberk Spezif Tuberkuloseforsch 1937; 89: 394-408.

15 Radomsky J, Becker HP, Hartel W. Pleuroporosität beim idiopatischen Spontanpneumothorax. [Pleural porosity in idiopathic spontaneous pneumothorax]. Pneumologie 1989; 43: 250-253.

16 Ohata M, Suzuki H. Pathogenesis of spontaneous pneumothorax: with special reference to the ultrastructure of emphysematous bullae. Chest 1980; 77: 771-776.

17 Janssen JP, Schramel FMNH, Sutedja TG, Cuesta MA, Oosterhuis WP, Postmus PE. Videothoracoscopic appearance of first and recurrent pneumothorax. Chest 1995; 108: 330-334.

18 Hatz RA, Kaps MF, Meimarakis G, Loehe F, Müller C, Fürst H. Long-term results after video-assisted thoracoscopic surgery for first-time and recurrent spontaneous pneumothorax. Ann Thorac Surg 2000; 70: 253-257.

19 Horio H, Nomori H, Kobayaski R, Narube T, Suemasu K. Impact of additional pleurodesis in video-assisted thoracoscopic bullectomy for primary spontaneous pneumothorax. Surg Endosc 2002; 16: 630-634.

20 Loubani M, Lynch V. Video-assisted thoracocopic bullectomy and acromycin pleurodesis: an effective treatment for spontaneous pneumothorax. Respir Med 2000; 94: 888-890.

21 Mitlehner W, Friedrich M, Dissmann W. Value of computer tomography in the detection of bullae and blebs in patients with primary spontaneous pneumothorax. Respiration 1992; 59: 221-227.

22 Lesur O, Delorme N, Fromaget JM, Bernardac P, Polu JM. Computed tomography in the etiologic assessment of idiopathic spontaneous pneumothorax. Chest 1990; 98: 341-347.

23 Bense L, Lewander R, Eklund G, Odont D, Hedentierna G, Wiman LG. Nonsmoking, non- $\alpha_{1}$-antitrypsin deficiencyinduced emphysema in nonsmokers with healed spontaneous pneumothorax, identified by computed tomography of the lungs. Chest 1993; 103: 433-438.

24 Smit HJM, Devillé WL, Schramel FM, Postmus PE. Spontaneous pneumothorax; predictable miniepidemics? Lancet 1997; 350: 1450.

25 Noppen M, Stratakos G, Verbanck S, D'Haese J, Meysman M, Vincken W. Fluoresceine-enhanced autofluorescence thoracoscopy in primary spontaneous pneumothorax. Am J Respir Crit Care Med 2004; 170: 680-682.

26 Luck SR, Raffensperger JG, Sullivan HJ, Gibson LE. Management of pneumothorax in children with chronic pulmonary disease. J Thorac Cardiovasc Surg 1977; 74: 834-839.

27 Spector ML, Stern RC. Pneumothorax in cystic fibrosis: a 26-year experience. Ann Thorac Surg 1989; 47: 204-207.

28 Dines DE, Clagett OT, Payne WS. Spontaneous pneumothorax in emphysema. Mayo Clin Proc 1970; 45: 481-487.

29 Sahn SA, Heffner JE. Spontaneous pneumothorax. N Engl J Med 2000; 342: 868-874. 
30 Bourgoin P, Cousineau G, Lemire P, Hebert G. Computed tomography used to exclude pneumothorax in bullous lung disease. J Can Assoc Radiol 1985; 36: 341-342.

31 Noppen M, Schramel F. Pneumothorax. Eur Respir Mon 2002; 22: 279-296.

32 Tumbarello M, Tacconelli E, Pirronti T, Cauda R, Ortona L. Pneumothorax in HIV-infected patients: role of Pneumocystis carinii pneumonia and pulmonary tuberculosis. Eur Respir J 1997; 10: 1332-1335.

33 Alifano M, Roth T, Broet SC, Schussler O, Magdeleinat P, Regnard JF. Catamenial pneumothorax: a prospective study. Chest 2003; 124: 1004-1008.

34 Andrivert P, Djdaini K, Teboul JL, Brochard L, Dreyfuss D. Spontaneous pneumothorax. Comparison of thoraric drainage versus immediate or delayed needle aspiration. Chest 1995; 108: 335-340.

35 Liu CM, Hang LW, Chen WK, Hsia TC, Hsu WH. Pigtail tube drainage in the treatment of spontaneous pneumothorax. Am J Emerg Med 2003; 21: 241-244.

36 Noppen M, Alexander P, Driesen P, Slabbynck $H$, Vertraeten A. Manual aspiration versus chest tube drainage in first episodes of primary spontaneous pneumothorax. A multicenter, prospective, randomized pilot study. Am J Respir Crit Care Med 2002; 165: 1240-1244.

37 Noppen M, Baumann MH. Pathogenesis and treatment of primary spontaneous pneumothorax: an overview. Respiration 2003; 70: 431-438.

38 Miller AC, Harvey JE, on behalf of Standards of Care Committee, Guidelines for the management of spontaneous pneumothorax. BMJ 1993; 307: 114-116.

39 Baumann MH, Strange C, Heffner JE, et al. for the ACCP pneumothorax consensus group. Management of spontaneous pneumothorax: an American College of Chest Physicians Delphi consensus statement. Chest 2001; 119: 590-602.

40 Jutley RS, Mason R, Cockburn JS. Discrepancies in the detection and management of spontaneous pneumothorax: eight years after publication of guidelines. Scot Med J 2003; 46: 111-113.

41 Mendis D, El-Shanawany T, Mathur A, Redington AE. Management of spontaneous pneumothorax: are British Thoracic Society guidelines being followed? Postgrad Med J 2002; 78: 80-84.

42 Falcoz PE, Binquet C, Clement F, et al. Management of the second episode of spontaneous pneumothorax: a decision analysis. Ann Thorac Surg 2003; 76: 1843-1848.

43 Almind $M$, Lange $P$, Viskum K. Spontaneous pneumothorax: comparison of single drainage, talc pleurodesis, and tetracycline pleurodesis. Thorax 1989; 44: 627-630.

44 Tschopp JM, Boutin C, Astoul P, et al. and the ESMEVAT team. Talcage by medical thoracoscopy for primary spontaneous pneumothorax is more cost-effective than drainage: a randomised study. Eur Respir J 2002; 20: 1003-1009.

45 Gobbel W. Spontaneous pneumothorax. J Thorac Cardiovasc Surg 1963; 46: 331-345.

46 Lippert HL, Lund O, Blegvad S, Larsen HV. Independent risk factors for cumulative recurrence rate after first spontaneous pneumothorax. Eur Respir J 1991; 4: 324-331.
47 Kroegel C, Antony VB. Immunobiology of pleural inflammation: potential implications for pathogenesis, diagnosis and therapy. Eur Respir J 1997; 10: 2411-2418.

48 Rodriguez-Panadero F, Antony VB. Pleurodesis: state of the art. Eur Respir J 1997; 10: 1648-1654.

49 Bresticker MA, Oba J, LoCicero J 3rd. Greene R. Optimal pleurodesis: a comparative study. Ann Thorac Surg 1993; 55: 364-366.

50 Colt HG, Russack V, Chiu Y, et al. A comparison of thoracoscopic talc insufflation, slurry, and mechanical abrasion pleurodesis. Chest 1997; 111: 442-448.

51 Heffner JE, Unruh LC. Tetracycline pleurodesis: adios, farewell, adieu. Chest 1992; 101: 5-6.

52 Carvalho P, Knight LL, Olson R, Crowley JJ, Hawk PA, Charan NB. Effects of erythromycin on the rabbit pleura: its potential role as a pleural sclerosant. Am J Respir Crit Care Med 1995; 151: 1228-1232.

53 Vargas FS, Teixeira LR, Silva LM, Carmo AO, Light RW. Comparison of silver nitrate and tetracycline as pleural sclerosing agents in rabbits. Chest 1995; 108: 1080-1083.

54 Vargas FS, Teixeira LR, Vaz MAC, et al. Silver nitrate is superior to talc slurry in producing pleurodesis in rabbits. Chest 2000; 118: 808-813.

55 Vargas FS, Teixeira LR, Antonangelo L, et al. Experimental pleurodesis in rabbits induced by silver nitrate and talc: 1-year follow-up. Chest 2001; 119: 1516-1520.

56 Wied U, Halkier E, Hoeier-Madsen K, Plucnar B, Rasmussen E, Sparup J. Tetracycline versus silver nitrate pleurodesis in spontaneous pneumothorax. J Thorac Cardiovasc Surg 1983; 86: 591-593.

57 Marchi E, Vargas FS, Acencio MM, et al. Talc and silver nitrate induce systemic inflammatory effects during the acute phase of experimental pleurodesis in rabbits. Chest 2004; 125: 2268-2277.

58 Bouros D, Froudarakis M, Siafakas NM. Pleurodesis: everything flows. Chest 2000; 118: 577-579.

59 Baumann $\mathrm{MH}$, Strange C. Treatment of spontaneous pneumothorax. A more aggressive approach? Chest 1997; 112: 789-804.

60 Berger R. Pleurodesis for spontaneous pneumothorax: will the procedure of choice please stand up? Chest 1994; 16: 992-994.

61 Aelony Y. Talc pleurodesis. Talc slurry versus talc poudrage. Chest 1995; 108: 289.

62 Colt H, Dumon JF. Development of a disposable spray canister for talc pleurodesis. A preliminary report. Chest 1994; 106: 1776-1780.

63 Mager HJ, Maesen B, Verzijlbergen F, Schramel F. Distribution of talc suspension during treatment of malignant pleural effusion with talc pleurodesis. Lung Cancer 2002; 36: 77-81.

64 Weissberg D, Refaely Y. Pneumothorax. Experience with 1,199 patients. Chest 2000; 117: 1279-1285.

65 el Khawand C, Marchandise FX, Mayne A, et al. Pneumothorax spontané: résultats du talcage sous thoracoscopie. [Spontaneous pneumothorax. Results of pleural talc therapy using thoracoscopy]. Rev Mal Respir 1995; 12: 275-281. 
66 Milanez de campos JR, Vargas FS, Werebe EC, et al. Thoracoscopic talc poudrage : a 15-year experience. Chest 2001; 119: 801-806.

67 Cardillo G, Facciolo F, Giunti R, et al. Videothoracoscopic treatment of primary spontaneous pneumothorax: a 6year experience. Ann Thorac Surg 2000; 69: 357-361.

68 Tschopp JM, Bolliger CT, Boutin C. Treatment of spontaneous pneumothorax: why not simple talc pleurodesis by medical thoracoscopy? Respiration 2000; 67: 108-111.

69 Rehse DH, Aye RW, Florence MG. Respiratory failure following talc pleurodesis. Am J Surg 1999; 177: 437-440.

70 Campos JR, Werebe EC, Vargas FS, Jatene FB, Light RW. Respiratory failure due to insufflated talc. Lancet 1997; 349: 251-252.

71 Kennedy L, Rush VW, Strange C, Ginsberg RJ. Pleurodesis using talc slurry. Chest 1994; 106: 342-346.

72 Rodriguez-Panadero F. Talc pleurodesis for treating malignant pleural effusions. Chest 1995; 108: 1178-1179.

73 Sahn SA. Talc should be used for pleurodesis. Am J Respir Crit Care Med 2001; 163: 2023-2026.

74 Kennedy L, Sahn SA. Talc pleurodesis for the treatment of pneumothorax and pleural effusion. Chest 1994; 106: 1215-1222.

75 Werebe EC, Pazetti R, Milanez-de Campos JR, et al. Systemic distribution of talc after intrapleural administration in rats. Chest 1999; 115: 190-193.

76 Ferrer J, Villarino MA, Tura JM, Traveria A, Light RW. Talc preparations used for pleurodesis vary markedly from one preparation to another. Chest 2001; 119: 1901-1905.

77 Fraticelli A, Robaglia-Schlupp A, Riera H, MonjanelMouterde S, Cau P, Astoul P. Distribution of calibrated talc after intrapleural administration: an experimental study in rats. Chest 2002; 122: 1737-1741.

78 Ferrer J, Montes JF, Villarino MA, Baeza B, Crespo M, Garcia-Valero J. Influence of particle size on extrapleural talc dissemination after slurry pleurodesis. Chest 2002; 122: 1018-1027.

79 Maskell NA, Lee YC, Gleeson FV, Hedley EL, Pengelly G, Davies RJ. Randomized trials describing lung inflammation after pleurodesis with talc of varying particle size. Am J Respir Crit Care Med 2004; 170: 377-382.

80 Viskum K, Lange P, Mortensen J. Long-term sequelae after talc pleurodesis for spontaneous pneumothorax. Pneumologie 1989; 43: 105-106.

81 Noppen M, Meysman M, d'Haese J, et al. Comparison of video-assisted thoracoscopic talcage for recurrent primary versus persistent secondary spontaneous pneumothorax. Eur Respir J 1997; 10: 412-416.

82 Baumann MH, Noppen M. Pneumothorax. Respirology 2004; 9: 157-164.

83 Lee P, Yap WS, Pek WY, et al. An audit of medical thoracoscopy and talc poudrage for pneumothorax prevention in advanced COPD. Chest 2004; 125: 1315-1320.

84 Le Chevalier B, Jehan A, Gallet E, Charbonneau PCB. Le talcage pleural par thoracoscopie dans le pneumothorax du grand insuffisant respiratoire obstructif. [Talc pleurodesis by thoracoscopy in pneumothorax accompanying severe respiratory insufficiency]. Réanim Soins Intens Méd Urg 1987; 3: 215-217.

85 Tschopp JM, Brutsche M, Frey JG. Treatment of complicated spontaneous pneumothorax by simple talc pleurodesis under thoracoscopy and local anaesthesia. Thorax 1997; 52: 329-332.

86 Massard G, Thomas P, Wihlm JM. Minimally invasive management for first and recurrent pneumothorax. Ann Thorac Surg 1998; 66: 592-599.

87 Olsen PS, Andersen HO. Long-term results after tetracycline pleurodesis in spontaneous pneumothorax. Ann Thorac Surg 1992; 53: 1015-1017.

88 van de Brekel JA, Dourkens VAM, Vanderschueren RGJRA. Pneumothorax. Results of thoracotomy and pleurodesis with talc poudrage and thoracotomy. Chest 1993; 103: 345-347.

89 Baumann MH, Strange C. The clinician's perspective on pneumothorax management. Chest 1997; 112: 822-828.

90 Nkere UU, Kumar RR, Fountain SW, Townsend ER. Surgical management of spontaneous pneumothorax. Thorac Cardiovasc Surg 1994; 42: 45-50.

91 Murray KD, Matheny RG, Howanitz EP, Myerowitz PD. A limited axillary thoracotomy as primary treatment for recurrent spontaneous pneumothorax. Chest 1993; 103: 137-142.

92 Simansky DA, Yellin A. Pleural abrasion via axillary thoracotomy in the era of video assisted thoracic surgery. Thorax 1994; 49: 922-923.

93 Körner H, Anderson KS, Stangeland L, Ellingsen I, Engedal H. Surgical treatment of spontaneous pneumothorax by wedge resection without pleurodesis or pleurectomy. Eur J Cardiothorac Surg 1996; 10: 656-659.

94 Donahue DM, Wright CD, Viale G, Mathisen DJ. Resection of pulmonary blebs and pleurodesis for spontaneous pneumothorax. Chest 1993; 104: 1767-1769.

95 Athanassiadi K, Kalavrouziotis G, Loutsidis A, Hatzimichalis A, Bellenis I, Exarchos N. Surgical treatment of spontaneous pneumothorax: ten-year experience. World J Surg 1998; 22: 803-806.

96 Cannon WB, Vierra MA, Cannon A. Thoracoscopy for spontaneous pneumothorax. Ann Thorac Surg 1993; 56: 686-687.

97 Mukaida T, Andou A, Date H, Motoi A, Shimizu N. Thoracoscopic operation for secondary pneumothorax under local and epidural anesthesia in high-risk patients. Ann Thorac Surg 1998; 65: 924-926.

98 de la Torre Bravos M, Rivas de Andrés JJ. Treatment of pneumothorax with VATS and bullectomy under local anesthesia. Ann Thorac Surg 1999; 68: 2383.

99 Kaiser D, Ennker IC, Hartz C. Video-assisted thoracoscopic surgery - indications, results, complications, and contraindications. Thorac Cardiovasc Surg 1993; 41: 330-334.

100 Mack MJ, Scruggs GR, Kelly KM, Shennib H, Landreneau RJ. Video-assisted thoracic surgery: has technology found its place? Ann Thorac Surg 1997; 64: 211-215.

101 Inderbitzi RGC, Leiser A, Furrer M, Althaus U. Three years experience in video-assisted thoracic surgery (VATS) for spontaneous pneumothorax. I Thorac Cardiovasc Surg 1994; 107: 1410-1415. 
102 Gossot D, Galetta D, Stern JB, et al. Results of thoracoscopic pleural abrasion for primary spontaneous pneumothorax. Surg Endosc 2004; 18: 466-471.

103 Liu HP, Lin PJ, Hsieh MJ, Chang JP, Chang CH. Thoracoscopic surgery as a routine procedure for spontaneous pneumothorax. Results from 82 patients. Chest 1995; 107: 559-562.

104 Naunheim KS, Mack MJ, Hazelrigg SR, et al. Safety and efficacy of video-assisted thoracic surgical techniques for the treatment of spontaneous pneumothorax. J Thorac Cardiovasc Surg 1995; 109: 1198-1204.

105 Bertrand PC, Regnard JF, Spaggiari L, et al. Immediate and long-term results after surgical treatment of primary spontaneous pneumothorax by VATS. Ann Thorac Surg 1996; 61: 1641-1645.

106 Mouroux J, Elkaïm D, Padovani B, et al. Video-assisted thoracoscopic treatment of spontaneous pneumothorax: technique and results of one hundred cases. J Thorac Cardiovasc Surg 1996; 112: 385-391.

107 Passlick B, Born C, Häussinger K, Thetter O. Efficiency of video-assisted thoracic surgery for primary and secondary spontaneous pneumothorax. Ann Thorac Surg 1998; 65: 324-327.

108 Rieger R, Woisetschläger R, Schrenk P, Wayand W. Thoracoscopic bleb resection selectively combined with pleurectomy for complicated spontaneous pneumothorax. Eur J Surg 1998; 164: 333-338.

109 Andrés B, Luján J, Robles R, Aguilar J, Flores B, Parrilla P. Treatment of primary and secondary spontaneous pneumothorax using videothoracoscopy. Surg Laparosc Endosc 1998; 8: 108-112.

110 Ayed AK, Al-Din J. The results of thoracoscopic surgery for primary spontaneous pneumothorax. Chest 2000; 118: 235-238.

111 Casadio C, Rena O, Giobbe R, Maggi G. Primary spontaneous pneumothorax. Is video-assisted thoracoscopy stapler resection with pleural abrasion the goldstandard? Eur J Cardiothorac Surg 2001; 20: 897-898.

112 Sawabata N, Ikeda M, Matsumura A, Maeda H, Miyoshi S, Matsuda H. New electroablation technique following the first-line stapling method for thoracoscopic treatment of primary spontaneous pneumothorax. Chest 2002; 121: 251-255.

113 Lang-Lazdunski L, Chapuis O, Bonnet PM, Pons F, Jancovici R. Videothoracoscopic bleb excision and pleural abrasion for the treatment of primary spontaneous pneumothorax: long-term results. Ann Thorac Surg 2003; 75: 960-965.

114 Margolis M, Gharagozloo F, Tempesta B, Trachiotis G, Katz NM, Alexander P. Video-assisted thoracic surgical treatment of initial spontaneous pneumothorax in young patients. Ann Thorac Surg 2003; 76: 1661-1664.

115 Czerny M, Salat A, Fleck T, et al. Lung wedge resection improves outcome in stage I primary spontaneous pneumothorax. Ann Thorac Surg 2004; 77: 1802-1805.

116 Chen JS, Hsu HH, Kuo SW, et al. Effects of additional minocycline pleurodesis after thoracoscopic procedures for primary spontaneous pneumothorax. Chest 2004; 125: 50-55.

117 Yamaguchi A, Shinonaga $M$, Tatebe S, Souma T, Tsuchida M, Saito A. Thoracoscopic stapled bullectomy supported by suturing. Ann Thorac Surg 1993; 56: 691-693.

118 Takeno Y. Thoracoscopic treatment of spontaneous pneumothorax. Ann Thorac Surg 1993; 56: 688-690.

119 Inderbitzi RGC, Furrer $M$, Striffeler $H$, Althaus U. Thoracoscopic pleurectomy for treatment of complicated spontaneous pneumothorax. I Thorac Cardiovasc Surg 1993; 105: 84-88.

120 Waller DA, Forty J, Soni AK, Conacher ID, Morrit GN. Videothoracoscopic operation for secondary spontaneous pneumothorax. Ann Thorac Surg 1994; 57: 1612-1615.

121 Horio H, Nomori H, Fuyuno G, Kobayashi R, Suemasu K. Limited axillary thoracotomy vs video-assisted thoracoscopic surgery for spontaneous pneumothorax. Surg Endosc 1998; 12: 1155-1158.

122 Sihoe ADL, Au SSW, Cheung ML, et al. Incidence of chest wall paresthesia after video-assisted thoracic surgery for primary spontaneous pneumothorax. Eur J Cardiothorac Surg 2004; 25: 1054-1058.

123 Hazama K, Akashi A, Shigemura N, Nakagiri T. Less invasive needle thoracoscopic laser ablation of small bullae for primary spontaneous pneumothorax. Eur J Cardiothorac Surg 2003; 24: 139-144.

124 Chen JS, Hsu HH, Kuo SW, et al. Needlescopic versus conventional video-assisted thoracic surgery for primary spontaneous pneumothorax: a comparative study. Ann Thorac Surg 2003; 75: 1080-1085.

125 Tagaya N, Kasama K, Suzuki N, Taketsuka S, Horie K, Kubota K. Video-assisted bullectomy using needlescopic instruments for sponaneous pneumothorax. Surg Endosc 2003; 17: 1486-1487.

126 Inderbitzi R, Furrer $M$. The surgical treatment of spontaneous pneumothorax by video-thoracoscopy. Thorac Cardiovasc Surg 1992; 40: 330-333.

127 Cardillo G, Facciolo F, Regal M, Carbone L, Corzani F, Ricci A. Recurrences following videothoracoscopic treatment of primary spontaneous pneumothorax: the role of redo-videothoracoscopy. Eur J Cardiothorac Surg 2001; 19: 396-399.

128 Nazari S, Buniva P, Aluffi A, Salvi S. Bilateral open treatment of spontaneous pneumothorax: a new access. Eur J Cardiothorac Surg 2000; 18: 608-610.

129 Wu YC, Chu Y, Liu YH, Yeh CH, Chen TP, Liu HP. Thoracoscopic ipsilateral approach to contralateral bullous lesion in patients with bilateral spontaneous pneumothorax. Ann Thorac Surg 2003; 76: 1665-1667.

130 Ayed AK. Bilateral video-assisted thoracoscopic surgery for bilateral spontaneous pneumothorax. Chest 2002; 122: 2234-2237.

131 Yim APC. Simultaneous vs staged bilateral video-assisted thoracoscopic surgery. Surg Endosc 1996; 10: 1029-1030.

132 Waller DA, Forty J, Moritt GN. Video-assisted thoracoscopic surgery versus thoracotomy for spontaneous pneumothorax. Ann Thorac Surg 1994; 58: 372-376.

133 Kim KH, Kim HK, Han JY, Kim JT, Won YS, Choi SS. Transaxillary minithoracotomy versus video-assisted thoracic surgery for spontaneous pneumothorax. Ann Thorac Surg 1996; 61: 1510-1512.

134 De Giacomo T, Rendina EA, Venuta F, Ciriaco P, Lena A, Ricci C. Video-assisted thoracoscopy in the management 
of recurrent spontaneous pneumothorax. Eur J Surg 1995; 161: 227-230.

135 Crisci R, Coloni GF. Video-assisted thoracoscopic surgery versus thoracotomy for recurrent spontaneous pneumothorax. A comparison of results and cost. Eur J Cardiothorac Surg 1996; 10: 556-560.

136 Miller JD, Simone C, Kahnamoui K, et al. Comparison of videothoracoscopy and axillary thoracotomy for the treatment of spontaneous pneumothorax. Am Surg 2000; 66: 1014-1015.

137 Jiménez-Merchán R, García-Díaz F, Arenas-Linares C, Girón-Arjona JC, Congregado-Loscertales M, Loscertales J. Comparative retrospective study of surgical treatment of spontaneous pneumothorax. Thoracotomy vs thoracoscopy. Surg Endosc 1997; 11: 919-922.

138 Atta HM, Latouf O, Moore JE, Caudill DR, Snyder AB. Thoracotomy versus video-assisted thoracoscopic pleurectomy for spontaneous pneumothorax. Am Surg 1997; 63: 209-212.

139 Cole FH Jr., Cole FH, Khandekar A, Maxwell JM, Pate JW, Walker WA. Video-assisted thoracic surgery: primary therapy for spontaneous pneumothorax? Ann Thorac Surg 1995; 60: 931-935.

140 Van Schil P. Cost analysis of video-assisted thoracic surgery versus thoracotomy: critical review. Eur Respir J 2003; 22: 735-738.

141 Torresini G, Vaccarili M, Divisi D, Crisci R. Is videoassisted thoracic surgery justified at first spontaneous pneumothorax? Eur J Cardiothorac Surg 2001; 20: $42-45$.

142 Morimoto T, Shimbo T, Noguchi Y, et al. Effects of timing of thoracoscopic surgery for primary spontaneous pneumothorax on prognosis and costs. Am J Surg 2004; 187: 767-774.
143 Schramel FMNH, Sutedja TG, Braber JCE, van Mourik JC, Postmus PE. Cost-effectiveness of video-assisted thoracoscopic surgery versus conservative treatment for first time or recurrent spontaneous pneumothorax. Eur Respir J 1996; 9: 1821-1825.

144 Smit HJM, Chatrou M, Postmus PE. The impact of spontaneous pneumothorax and its treatment on the smoking behaviour of young adult smokers. Respir Med 1998; 91: 1132-1136.

145 Soulsby T. British Thoracic Society guidelines for the management of spontaneous pneumothorax: do we comply with them and do they work? J Accid Emerg Med 1998; 15: 317-321.

146 Selby CD, Sudlow MF. Deficiencies in the management of spontaneous pneumothorax. Scot Med J 1994; 39: 75-76.

147 Daly RC, Mucha P, Pairolero PC, Farnell MB. The risk of percutaneous chest tube thoracostomy for blunt thoracic trauma. Ann Emerg Med 1985; 14: 865-870.

148 Miller KS, Sahn FA. Chest tubes; indications, technique, management and complications. Chest 1987; 91: 258-264.

149 Chan L, Reilly KM, Henderson C, Kahn F, Salluzo RF. Complication rates of tube thoracostomy. Am J Emerg Med 1997; 15: 368-370.

150 Baldt MM, Bankier AA, Germann PS, Poschl GP, Skrbensky GT, Herold CJ. Complications after emergency tube thoracostomy: assessment with CM. Radiology 1995; 195: 539-543.

151 Tschopp JM, Frey JG. Treatment of primary spontaneous pneumothorax by simple talcage under medical thoracoscopy. Monaldi Arch Chest Dis 2002; 57: 88-92.

152 LoCicero J 3rd. Video-assisted thoracoscopy's anniversary. Chest 1997; 111: 268-269.

153 Heffner JE, Huggins JT. Management of secondary spontaneous pneumothorax: there's confusion in the air. Chest 2004; 125: 1190-1192. 